\title{
Xeractinol - A New Flavanonol C-glucoside from Paepalanthus argenteus var. argenteus (Bongard) Hensold (Eriocaulaceae)
}

\author{
Anne Lígia Dokkedal, ${ }^{*, a}$ Francisco Lavarda, ${ }^{a}$ Lourdes Campaner dos Santos ${ }^{b}$ and Wagner Vilegas ${ }^{b}$ \\ ${ }^{a}$ Faculdade de Ciências, Universidade Estadual Paulista, CP 473, 17033-360 Bauru - SP, Brazil \\ ${ }^{b}$ Instituto de Química, Universidade Estadual Paulista, CP 355, 14801-970 Araraquara - SP, Brazil
}

\begin{abstract}
Um novo composto, isolado a partir do extrato metanólico das folhas de Paepalanthus argenteus var. argenteus (Bongard) Hensold foi caracterizado como xeractinol, um novo diidroflavonol C-glucosilado. Sua estrutura foi elucidada com base em extensiva análise espectroscópica (RMN uni- e bidimensionais, EM, HREIMS, IV, UV). Cálculos ab initio de estrutura eletrônica corroboram nossa proposição para a estrutura molecular. O diidroflavonol aqui isolado pode servir como marcador taxonômico de Paepalanthus subg. Xeractis, uma vez que este flavonóide não foi encontrado em nenhum outro taxon de Eriocaulaceae.
\end{abstract}

New compound isolated from methanolic extract from the leaves of Paepalanthus argenteus var. argenteus (Bongard) Hensold was characterized as xeractinol, a new dihydroflavonol C-glucoside. The structure was elucidated on the basis of extensive spectroscopic analysis (1D and 2D NMR, MS, HREIMS, IR and UV). Ab initio electronic structure calculations support our proposal to the molecular structure. The dihydroflavonol herein isolated may serve as taxonomic marker of Paepalanthus subgenus Xeractis, because this flavonoid have not been reported in any other taxon of Eriocaulaceae.

Keywords: Paepalanthus argenteus var. argenteus, Eriocaulaceae, dihydroflavonol, xeractinol, $a b$ initio calculations

\section{Introduction}

Eriocaulaceae is a pantropical, predominantly herbaceous monocotyledonous family, comprising around 1200 species included in 10 genera. $^{1}$ They are frequent components of the vegetation in montane shallow pools or swamps, especially on sandy ground. This family is characterized as a monophyletic taxon with the following synapomorphies: very small, unisexual, white flowers, in dense capitula, with only one ovule per locule, and spiraperturate pollen. ${ }^{1}$

Eriocaulaceae is a rich source of phenolic compounds, like naphthopyranones and glycosilated flavonóides..$^{2-5}$ We have already reported that flavonoids and naphthopyranones are of taxonomic significance to the systematic of Eriocaulaceae. ${ }^{6,7}$ We report here the isolation and characterization of xeractinol, a new flavanonol from the leaves of Paepalanthus argenteus var. argenteus (Bongard) Hensold.

*e-mail: dokkedal@fc.unesp.br

\section{Results and Discussion}

The flavanonol C-glucoside 1 (xeractinol) was obtained directly from the fractionation of the methanolic extract of leaves of $P$. argenteus var. argenteus by column chromatography on Sephadex LH-20 (Pharmacia) eluted with $\mathrm{MeOH}$. It gave a yellow spot on TLC under UV light. The IR spectrum exhibited bands at $3425(\mathrm{OH})$ and at $1656(\mathrm{C}=\mathrm{O})$ and $1604 \mathrm{~cm}^{-1}(\mathrm{C}=\mathrm{C})$. The UV spectra showed absorptions bands at 287 and $330 \mathrm{~nm}$. The ES-MS spectrum of $\mathbf{1}$ showed a pseudo molecular ion $[\mathrm{M}+\mathrm{H}]^{+}$at $m / z 467$, consistent with a molecular formula $\mathrm{C}_{21} \mathrm{H}_{22} \mathrm{O}_{12}$. The $[(\mathrm{M}+\mathrm{H})-120]^{+}$ion was formed by an A-type cleavage, which is consistent with a C-6 glucoside substituent. ${ }^{9}$ The peak at $m / z, 177$ is due to the ion with formula $\mathrm{C}_{9} \mathrm{H}_{15} \mathrm{O}_{5}$, resulting from the retro-Diels-Alder fragmentation of $\mathbf{1}$ in which part of the sugar moiety is bounded to the Aring, thus evidencing that the sugar moiety is linked to this part of the molecule. The $[(\mathrm{M}+\mathrm{H})-90]^{+}$ion corresponds to the cleavage of the B-ring. The negative HREIMS [M$\mathrm{H}]^{-}$at $m / z, 465.1039$ suggest $\mathrm{C}_{21} \mathrm{H}_{22} \mathrm{O}_{12}$ to be the molecular 
formula. The ${ }^{1} \mathrm{H}$ NMR of $\mathbf{1}$ showed two doublets with $J$ $11 \mathrm{~Hz}$ at $\delta 4.95$ and at $\delta 4.46$, related to the $\mathrm{H}-2$ and $\mathrm{H}-3$, respectively, of a 3-hydroxy substituted flavanone. ${ }^{9}$ The singlet at $\delta 5.92$ was assigned to $\mathrm{H}-8$. The doublet at $\delta$ $6.74(2 \mathrm{H}, J 2.0)$ is related to H-2' and H-6' (magnetically equivalent) and the doublet at $\delta 6.87$ ( $J$ 2.0) is related to H-4'. The glucose moiety was confirmed in C-linkage by the presence of an anomeric proton at $\delta 4.48(J 10.0)$ as well as from six other signals between $\delta 3.67$ and $\delta 3.98$. The ${ }^{13} \mathrm{C}$ NMR (DMSO $d_{6}$ ) spectrum showed 21 signals, six of which could be assigned to a $\beta$-D-glucopyranosyl moiety and fifteen other signals were similar to those of a flavanonol moiety. ${ }^{8,12}$ Aglycone moiety 197.9 (C-4), 166.2 (C-7), 162.7 (C-5), 161.4 (C-9), 145.9 (C-3'), 145.1 (C5'), 128.1 (C-1'), 119.5 (C-6'), 115.4 (C-4'), 115.3 (C2'), 106.1 (C-6), 100.3 (C-10), 94.9 (C-8), 83.1 (C-2), 71.7 (C-3); sugar moiety 81.6 (C-5"), 79.2 (C-3"), 73.1 (C-1"), 70.8 (C-4"), 70.5 (C-2"), 61.7 (C-6a"). DEPT experiment allowed differentiating between $\mathrm{C}, \mathrm{CH}$ and $\mathrm{CH}_{2}$. The C-2 signal appeared at $\delta 83.1$ and the C-3 signal at $\delta$ 71.7. According to these values, aryl and hydroxyl substituents at C-2 and C-3 are equatorially oriented (2,3trans). ${ }^{8}$ The HMQC spectrum showed all the direct correlations between $\mathrm{C}$ and $\mathrm{H}$. The $\mathrm{HMBC}$ experiment showed the coupling between $\mathrm{H}-1$ "' $(\delta$ 4.48) and C-6 $(\delta$ $106.1), \mathrm{C}-7$ ( $\delta$ 166.2) and $\mathrm{C}-5$ ( $\delta$ 162.7). The HMBC experiment also showed correlations between the low field OH-5 signal $(\delta$ 12.41) and C-5 ( $\delta$ 162.7), C-6 $(\delta$ 106.1) and $\mathrm{C}-10(\delta 100.3)$, confirming that the glucose moiety is bonded to C-6; between H-4' $(\delta$ 6.87) and C-3' $(\delta$ 145.5), C-5' $(\delta$ 145.1), C-2' $(\delta$ 115.3), C-6' $(\delta$ 119.5); between $\mathrm{H}-2(\delta$ 4.95) and C-6' $(\delta$ 119.5), C-2' $(\delta$ 115.3), C-1' $(\delta$ 128.1), $\mathrm{C}=\mathrm{O}(\delta$ 197.9); between $\mathrm{H}-3(\delta$ 4.46) and $\mathrm{C}-1$ ' $(\delta$ 128.1), $\mathrm{C}=\mathrm{O}\left(\delta\right.$ 197.9); between $\mathrm{H}-2^{\prime}$ ' $(\delta$ 6.74) and $\mathrm{C}-1$ ' $(\delta$ $128.1), \mathrm{C}-4$ ' $(\delta$ 115.4); between H-6' $(\delta$ 6.74) and C-1' $(\delta$ $128.1), \mathrm{C}-4$ ' $(\delta$ 115.4); between $\mathrm{H}-8(\delta$ 5.92) and C-6 $(\delta$ $106.1), \mathrm{C}-9$ ( $\delta$ 161.4) and C-10 ( $\delta$ 100.3).

Considering the two hydrogen atoms bonded to carbon 2 and 3, there are four possible isomers. The isomer seen in Figure 1 was named trans a. Considering this structure, the isomer trans b has the hydrogen atoms with changed positions relative to the plane of the ring to which they are attached; to cis a the hydrogen attached to carbon 3 changes position with the hydroxyl group. Considering cis a, in cis b both hydrogen change position relative to the plane of the ring. In order to know which one is the most stable isomer, we made use of quantum chemistry theory. The results (Table 1) disfavor the cis configurations, once the difference in total energy between the trans and cis configurations is high enough to prevent the cis configurations to occur.
So, at least is possible to conclude that one of the trans configurations is the most probable structure, once the difference in total energy between trans-a and trans-b is very low. Thus, 1 was identified as $(2 \mathrm{R}, 3 \mathrm{R})-2-(3,5-$ dihydroxyphenyl)-6- $\beta$-D-glucopyranosyl-2,3-dihydro3,5,7-trihydroxy-4H-1-benzopyran-4-one (xeractinol), Figure 1.

Table 1. Differences of theoretical total energy $\left(\mathrm{kJ} \mathrm{mol}^{-1}\right)$, taking trans-a as the reference level

\begin{tabular}{lcccc}
\hline Isomer & trans-a & trans $-\mathrm{b}$ & cis-a & cis-b \\
\hline TE-TE $_{\text {trans-a }}$ & 0.000 & 0.196 & 20.554 & 23.828 \\
\hline
\end{tabular}<smiles>O=C1c2c(cc(O)c(C3OC(CO)C(O)C(O)C3O)c2O)O[C@H](c2cc(O)cc(O)c2)C1O</smiles>

Figure 1. Xeractinol (1) from Paepalanthus argenteus var. argenteus.

According to previous works, $P$. subg. Platycaulon is characterized by naphthopyranone derivatives and 7-methoxy flavonol derivatives, ${ }^{3,4} P$. sect. Actinocephalus presents mainly flavonol glycosides and acylated flavonols; ${ }^{2}$ in $P$. subg. Xeractis 6-methoxyflavone derivatives are major constituents as well as in Leiothrix and Syngonanthus, which also contain flavones rather than flavonols. ${ }^{6,7}$ The dihydroflavonol herein isolated may serve as taxonomic marker of Paepalanthus subg. Xeractis, since this type of flavonoid have not been reported in any other taxon of Eriocaulaceae.

\section{Experimental}

\section{Plant material}

Paepalanthus argenteus var. argenteus was collected at Serra do Cipó, Minas Gerais, Brazil in February 1998. Dr. Nancy Hensold (Field Museum, Chicago) carried out identification of plant material. Voucher specimens were deposited at Herbarium SPF, Brazil (P. argenteus var. argenteus, SANO 920).

\section{Extraction and isolation}

The separated powdered leaves of the species were extracted with $\mathrm{CHCl}_{3}$ and then with $80 \% \mathrm{MeOH}$ 
(maceration at room temp., one week each solvent). The solvents were evaporated in vacuum yielding black syrups. Two $\mathrm{g}$ of the $80 \% \mathrm{MeOH}$ extract of P. argenteus var. argenteus were redissolved in $\mathrm{MeOH}$ and subjected to gel permeation column chromatography on Sephadex LH20 (Pharmacia) eluted with $\mathrm{MeOH}$ affording substance $\mathbf{1}$ $(140 \mathrm{mg})$. Two other compounds were isolated after purification by HPLC (Dynamax RP-18, Varian $8 \mu \mathrm{m}, 30$

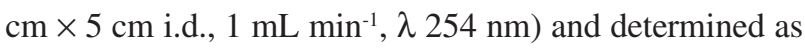
being quercetagetin 7 -methyl ether 3-O-neohesperidoside (32 $\mathrm{mg})$ and 3,4-dihydro-10-hydroxy-7-methoxy-3methyl-1H-3,4-dihydro-naphtho-[2,3c]-pyran-1-one-9-O$\beta$-D-allopyranosyl (1-6)- $\beta$-D-glucopyranoside (27mg) by their spectrometric data. ${ }^{3,4,8,9}$ NMR spectra in DMSO- $d_{6}$ were obtained using a Varian INOVA 500 spectrometer, operating at $500 \mathrm{MHz}$ for ${ }^{1} \mathrm{H}$ and $125 \mathrm{MHz}$ for ${ }^{13} \mathrm{C}$. The DEPT (distortionless enhancement by polarization transfer) experiments were performed using a transfer pulse of $135^{\circ}$. Polarization transfer delays were adjusted to average $\mathrm{CH}$ coupling of $135 \mathrm{~Hz} .{ }^{1} \mathrm{H}-{ }^{-} \mathrm{H}$ DFQ-COSY, ${ }^{1} \mathrm{H}-{ }^{13} \mathrm{C}$ HSQC, HMBC and 1D-TOCSY experiments were obtained using conventional pulse sequences. Low resolution ES-MS spectra was performed in a Fisons VG Platform spectrometer in the positive mode (100V), the samples were dissolved in $\mathrm{MeOH}$ and injected directly. HREIMS of 1 was performed by using a ultrOTOF ${ }_{Q}-$ ESI-TOF Mass Spectrometer Bruker Daltonics (Billerica, MA, USA) instrument in the negative mode; samples were dissolved in $\mathrm{MeOH}: \mathrm{H}_{2} \mathrm{O}$ (80:20). IR: KBr. UV: $\mathrm{MeOH}$. TLC: silica gel $60 \mathrm{H}$ (Merck, 10-40 $\mu \mathrm{m}$ ). The flavonoids were detected with NP/PEG reagent under UV light. ${ }^{10}$ Quantum chemistry theory calculations, including geometry optimization and electronic structure, were carried out employing ab initio B3LYP/6-31G(d) density functional theory methodology with the GAMESS package. ${ }^{11}$ The calculations for all isomers were done in vacuo.

\section{Supplementary Information}

Supplementary data are available free of charge at http://jbcs.sbq.org.br, as PDF file.

\section{Acknowledgments}

The authors thank the financial support provided by FAPESP, CNPq and FUNDUNESP and the Dr. Norberto Peporini Lopes (FCFRP - USP) for the use of HREIMS equipment.

\section{References}

1. Giulietti, A. M.; Amaral, M. C.; Bittrich, V.; Kew Bull. 1995, 50,55 .

2. Andrade, F. D. P.; Santos, L. C.; Dokkedal, A. L.; Vilegas, W.; Phytochemistry 1999, 51, 41.

3. Vilegas, W.; Dokkedal, A. L.; Rastrelli, L.; Piacente, S.; Pizza, C.; J. Nat. Prod. 1999, 62, 746.

4. Vilegas, W.; Nehme, C. J.; Dokkedal, A. L.; Piacente, S.; Rastrelli, L.; Phytochemistry 1999, 51, 403.

5. Dokkedal, A. L.; Salatino, A.; Biochem. Syst. Ecol. 1992, 20, 31.

6. Dokkedal, A. L.; Ph.D. Thesis, Universidade Estadual Paulista, Brazil, 2000.

7. Dokkedal, A. L.; Sano, P.T.; Vilegas, W.; Biochem. Syst. Ecol. 2004, 32, 503.

8. Agrawal, P. K.; Carbon 13 NMR of Flavonoids, $1^{\text {st }}$ ed., Elsevier: Amsterdam, 1989.

9. Harborne, J.B.; The Flavonoids: Advances in Research, $1^{\text {st }}$ ed., Chapman \& Hall: London, 1996.

10. Wagner, H. M.; Bladt, S.; Zgainski, E. M.; Plant Drug Analysis, $1^{\text {st }}$ ed., Springer: Berlin, 1984.

11. Schmidt, M. W.; Balbridge, K. K.; Boatz, J. A.; Elbert, S. T.; Gordon, M. S.; Jensen, J. J.; Koseki, S.; Matsunaga, N.; Nguyen, K. A.; Su, S.; Windus, T. L.; Dupuis, M.; Montgomery, J. A.; J. Comput. Chem. 1993, 14, 1347.

12. Mbafor, J.T.; Fomum, Z.T.; J. Nat. Prod. 1989, 52, 417.

Received: February 7, 2006

Web Release Date: March 16, 2007

FAPESP helped in meeting the publication costs of this article. 